\title{
Preterm Neonatal Sepsis: Associated Risk Factors and Microbial Profiles at Kitale County Hospital New-born Unit, Western Kenya
}

\author{
Everlyne P. Kweyu ${ }^{1 *} \quad$ Eric Omori Omwenga ${ }^{2} \quad$ Geoffrey K. Maiyoh ${ }^{3}$ \\ 1.Department of Applied Health Sciences, School of Health Sciences, Kisii University. P.O. BOX 408-40200, \\ Kisii, Kenya \\ 2.Department of Medical Microbiology \& Parasitology, School of Medicine, Kisii University. P.O. BOX 408- \\ 40200, Kisii, Kenya \\ 3.Department of Biochemistry and Clinical Chemistry. School of Medicine, Moi University, P.O. BOX 4606- \\ 30100 Eldoret, Kenya
}

\begin{abstract}
Neonatal sepsis is a major concern with maternal and neonatal risk factors greatly being associated with development of neonatal sepsis. In this study, we sort to determine the associated risk factors and microbial profiles at Kitale County Hospital $(\mathrm{KCH})$ new-born unit in Western Kenya. Data was collected from 181 eligible preterm neonates and cultured using standard protocols. A prevalence of $22.7 \%$ was found with majority of Gram positive 35 (85.4\%) while Gram negative were $6(14.6 \%)$. Coagulase Negative Staphylococcus (CoNS) were 31 (75.6\%) with Staphylococcus epidermidis 19 (46.3\%) being the majority. Mode of delivery, Prolonged Rupture of Membranes (PROM), foetal distress, low birth weight and poor breast feeding were major risk factors associated with neonatal sepsis at $\mathrm{KCH}$. There is therefore need to assess the correlation between the specific maternal and neonatal risk factors with common circulating bacterial profiles at $\mathrm{KCH}$ new born unit.
\end{abstract}

Keywords: Preterm neonate, Neonatal sepsis, New-born unit, Microbial profiles and characteristics. Western Kenya.

DOI: $10.7176 / \mathrm{JHMN} / 89-06$

Publication date:May $31^{\text {st }} 2021$

\section{Introduction}

Globally approximately 15 million premature infants are born yearly however, majority of these babies die shortly after birth due to Neonatal Sepsis (NS). Some may suffer from some type of lifelong physical, neurological, or educational impairment, which generates high costs in terms of their management. Incidence is highest in neonates and children which accounts to $47 \%$ of total infant deaths among the under-five due to preterm related complications (Howson et al., 2014; UNICEF, 2020). Neonatal sepsis (NS) is defined as an infant $(<90$ days) blood infection with systematic signs and symptoms of septicaemia in the first one month of life (Nathan, 2019; Masanja et al., 2019).

Neonatal Sepsis (NS) is characterized by such symptoms like respiratory distress, septicaemia, pneumonia, and meningitis (Nathan, 2019). It is more common in premature infants with a low birth weight (Stoll et al., 2010). Low birth weight, low gestational age and parenteral nutrition are the common risk factors associated with the increased severity of the two syndromes hence need of invasive monitoring and supportive care (Adams-Chapman et al, 2008). These risk factors are prominent with the premature infant and involve all level of host defence, including cellular, humoral, barrier function etc. (Groer et al., 2015). These new-borns require long hospitalization periods and are subjected to several treatments and invasive procedures that put them at a higher risk of acquiring infection.

Factors such as neonate age, birth asphyxia, Prolonged Rupture of Membranes (PROM), preterm births and infections have been documented to be the main causes of neonatal sepsis among the preterm neonates (UNICEF, 2020). Maternal risk factors like mode of delivery makes a neonate more susceptible to early onset sepsis, due to their potential risk for complications to the neonate and the mother resulting to infections (Murthy et al., 2019; Nyma, 2020). While neonatal risk factors such as neonatal age and resuscitation at birth, were found to contribute to occurrence of neonatal sepsis as the neonate's immune system is compromised leading to acquisition of infections. These factors were found to have a strong association on the development of neonatal sepsis (Adatara et al., 2019).

Neonatal sepsis has been documented to be caused by various bacterial, viral and fungal pathogens depending on different times and regions (Dolin et al., 2019). Among the bacterial pathogens that have been commonly associated with neonatal sepsis include Klebsiella pneumoniae, Escherichia coli, Coagulase Negative Staphylococcus (CoNS), Staphylococcus aureus and Streptococcus agalactiae (Guo et al., 2019). Fungal pathogens, commonly Candida species like Candida albicans, Candida parapsilosis and Candida krusei have also been associated with late-onset sepsis due to maternal fungal colonization and vaginal route of delivery (Shane et al., 2017; Ahmed et al., 2019). While viral pathogens such as herpes simplex viruses, enteroviruses and parenchoviruses have been associated with sepsis in neonates (Singh, 2020). Among the bacterial isolates 
Gram positive pathogens have been documented as the leading causes of neonatal sepsis with obstetric factors being highly associated with the development of neonatal sepsis. However, in some studies the prevalence of NS causing bacteria have been documented to be high with Coagulase Negative Staphylococcus (CoNS) being the majority from all the isolated pathogens (Sorsa, 2019).

Globally about $47 \%$ of neonatal deaths occur due to preterm and related complications (UNICEF 2020). The case fatality risk associated with severe bacterial infections in infants in the first month of life is $9.8 \%$ in Sub-Saharan Africa, South and Latin America (Seale et al., 2014). Incidence of culture proven early-onset sepsis in the United States is approximately 0.3-2 per 1000 live births (Nathan, 2019). Africa countries have also not been left behind as they have documented high prevalence/incidence rates. For instance, in East Africa, prevalence of neonatal sepsis from various studies has been documented with estimates ranging from $4.7 \%$ to 77.9\% (Berkley et al, 2005; Gebrehiwot et al, 2012). For instance, in one study carried out in Ethiopia, the prevalence of neonatal sepsis among 351 neonates admitted in NICU Arbaminch general hospital Southern Ethiopia was 78.3\% (Erkihun et al., 2019). In Kenya neonatal mortality rate by 2019 was at 21 deaths per 1000 livebirths (UNICEF, 2020) while prevalence of sepsis was estimated to be $28.6 \%$ at the new born unit of Kenyatta National hospital in central Kenya (Geyt \& Hauck, 2016; Okube \& Komen, 2020).

Antimicrobial agents offer recommendable reduction of NS. Reports on emergence of drug and multi-drug (MDR) resistant bacteria strains causing neonatal sepsis are on the increase globally. Effective antimicrobial agents against the common pathogens causing neonatal sepsis are available like intrapartum antibiotic prophylaxis, which are able to improve the immune system by preventing and also treating neonatal sepsis. However, these measures are not documented in the guidelines for the management of neonatal sepsis (Esposito \& Principi., 2019). Few Studies on NS are available in African continent which places need for more local data generation to inform policy and practice on the early management and treatment of neonatal sepsis. This study therefore, sought to find out associated risk factors and microbial profiles among preterms in new-born unit in Trans Nzoia County in Western Kenya.

\section{Materials and Methods}

\subsection{Study ethical approvals}

This study was approved by the instructional research and ethical committee of MU/MTRH (FAN: IREC 3174) on $6^{\text {th }}$ December 2018, The National Commission for Science, Technology and Innovation (NACOSTI/P/19/80813/27724 on $29^{\text {th }}$ January, 2019). Additional approvals were obtained from the Ministry of Interior and Coordination of National Government (TNZC/CONF/ED.12/2/VOL.II/107 on 27 ${ }^{\text {th }}$ March, 2019), Ministry of Education Science and Technology State Department of early learning and basic Education (TNZ/CNT/CDE/R.GEN/1/VOL.II/14 on 27 March 2019) and from County Government of

Trans Nzoia, State Department of Health (CGTN/HS/COHCS/2018 on 17 th $^{\text {th }}$ April, 2019).

Confidentiality of information obtained from the mother was maintained.

\subsection{Study site}

The study was conducted in Trans Nzoia county at Kitale County Hospital (KCH) New-born Unit (NBU). Trans Nzoia county is located in Western part of Kenya, it borders Uganda to the North West and approximately 397 $\mathrm{km}$ from Nairobi (See Figure 1).

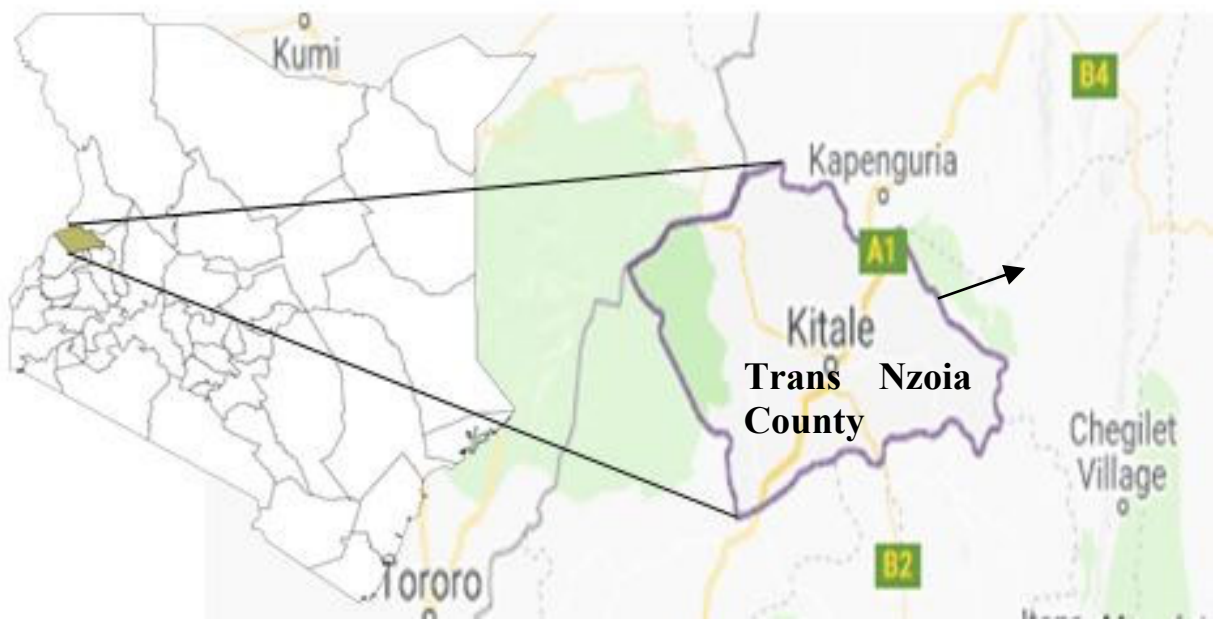

Figure 1: Map of Kenya showing location of Trans Nzoia County and Kitale (Modified from: (https://lands.go.ke/wp-content/uploads/2018/11/ The-map-of-Kenya.pdf) 


\subsection{Study population}

i. Inclusion criteria

Preterm neonates with a gestation age of less than 36 weeks presenting with signs and symptoms of neonatal sepsis (NS), admitted in the new born unit at $\mathrm{KCH}$ during the study period were included to this study. NS was determined based on criteria by Lutsar et al., 2014 and included the presence of at least 3 out of the following four presentations:

- Presence of risk factors of sepsis e. g. prematurity and chorioamnionitis.

- Presence of two or more clinical signs of sepsis such as poor reflexes, lethargy, respiratory distress, bradycardia, apnea, convulsions.

- Low haemoglobin (haematocrit) levels.

- Abnormal core temperature $\left(>38^{\circ} \mathrm{C}\right)$.

ii. Exclusion criteria

Preterm neonates whose mothers did not give consent for their participation and those who were on antibiotic treatment were excluded from the study.

\subsection{Sample size calculation}

A prevalence rate of $13 \%$ bacteraemia was used to calculate the sample size in accordance to the findings of a study conducted at Kilifi District Hospital, Kenya (Berkley et al., 2005). Sample size was determined using Cochran's formula of 1997 (Cochran, 2007) giving a 181 as the minimum number of participants required in the study.

\subsection{Study design}

Descriptive cross-sectional study was conducted between May 2018 to June 2020. A total of 181 mothers consented into the study and were interviewed using well-structured questionnaires to obtain data on demography and medical history. Blood samples were drawn for microbial and biochemical laboratory analysis.

\subsection{Laboratory analyses}

2.6.1 Blood collection

Blood sample $(3 \mathrm{ml})$ was collected aseptically in triplicates and inoculated into diphasic blood culture bottle (Himedia-India) and labelled with study number, date and time of sample collection. The samples were sent immediately to the laboratory for culture.

\subsubsection{Bioassays}

i. Blood culturing

Blood culturing was done on the blood samples obtained from the children using established protocols as applied before (Wayne, 2007). Briefly, the collected blood samples were immediately cultured in diphasic blood culture bottles (prepared as per the manufacturer's instructions) using continuously blood cultured method, incubated at $37^{\circ} \mathrm{C}$ and monitored daily for any changes (Haemolysis, Clotting and turbidity). Positive blood cultures were sub-cultured on 5\% sheep blood agar and chocolate blood agar and were incubated aerobically and anaerobically at $37^{\circ} \mathrm{C}$ for 18 hours.

ii. Gram staining

Gram staining was performed on positive blood cultures for identification of pathogens using established protocols as used before (Behera et al., 2010; Hussein, 2016). A bacterial suspension was prepared from 1-2 bacterial colonies and used to prepare a smear on a microscope slide using a sterile inoculating loop before staining. Staphylococcus aureus (ATCC 25923) and Escherichia coli (ATCC 25922) were used as positive control and negative control respectively.

iii. Biochemical tests

Identification of pathogens of interest causing neonatal sepsis was done using various biochemical tests in triplicates.

\subsection{Statistical analysis}

Descriptive and inferential statistics were performed on the data. Fisher's exact test and odds ratio (OR) analysis was used to test the distribution differences in variables between maternal and neonatal factors and neonatal sepsis (positive blood culture) at the significance level of $\mathrm{P}<0.05$. All statistical analyses were performed using IBM SPSS Statistics v21.

\subsection{Ethical approvals}

This study was approved by the instructional research and ethical committee of MU/MTRH (FAN: IREC 3174) on $6^{\text {th }}$ December 2018, The National Commission for Science, Technology and Innovation (NACOSTI/P/19/80813/27724 on $29^{\text {th }}$ January, 2019). Additional approvals were obtained from the Ministry of 
Interior and Coordination of National Government (TNZC/CONF/ED.12/2/VOL.II/107 on 27 ${ }^{\text {th }}$ March, 2019), Ministry of Education Science and Technology State Department of early learning and basic Education (TNZ/CNT/CDE/R.GEN/1/VOL.II/14 on 27 March 2019) and from County Government of Trans Nzoia, State Department of Health (CGTN/HS/COHCS/2018 on 17 $7^{\text {th }}$ April, 2019). Confidentiality of information obtained from the mother/ guardian was maintained.

\section{Results}

\subsection{Demographic characteristics}

Majority of the neonates were female $107(59.1 \%)$ while $74(40.9 \%)$ were male. Their age ranged from $\leq 24$ hours to ten-day olds with a mean age of $2.48 \pm 1.899$ days. Their mothers' gestation age ranged from 30 to 36 completed weeks with a mean of $34.10 \pm 1.74$. The neonates' body temperature ranged from 38.0 to $39.6^{\circ} \mathrm{C}$ with a mean of $38.6 \pm 0.3^{\circ} \mathrm{C}$, their birth weight mean was $2142 \pm 482.01$ grams while their first day of presentation with signs of sepsis had a mean age $2.3 \pm 1.9$ days. The summary of demographic findings are as summarized in

Table 3.1.

Table 3.1: Neonatal demographics

\begin{tabular}{|c|c|c|c|c|}
\hline Variables & Frequency $(\mathrm{N}=181)$ & Percent (\%) & Mean & SD \\
\hline \multicolumn{5}{|l|}{ a. Gender } \\
\hline i. Male & 74 & 40.9 & & \\
\hline ii. Female & 107 & 59.1 & & \\
\hline b. Age of the neonates (days) & & & 2.48 & \pm 1.899 \\
\hline c. Gestational age at delivery (weeks) & & & 34.10 & \pm 1.74 \\
\hline d. Body temperature $\left({ }^{0} \mathrm{C}\right)$ & & & 38.6 & \pm 0.3 \\
\hline e. Birth weight (Grams) & & & 2142 & \pm 482.01 \\
\hline f. Age (in day) of first presentation with sepsis & & & 2.35 & \pm 1.9 \\
\hline
\end{tabular}

\section{SD-Standard Deviation}

\subsection{Antenatal History}

This study also found out mothers' past antenatal medical history and the findings are as summarized in Table 3.2 below. Majority of the mothers 149 (82\%) had spontaneous virginal delivery (SVD) compared to 32 (18\%) caesarean section (CS) mode. On the other hand, four (4) mothers accounting for $2.2 \%$ had a history of unspecified urinary tract infection during pregnancy while those with any type of illness in pregnancy were 28 (15.5\%). Two (2) mothers tested positive for KHAN test while 4 experienced discharge during pregnancy. A further $8(4.4 \%)$ had premature rapture of membranes.

Table 3.2: Mother's past medical history (antenatal history)

Variables
Frequency $(\mathbf{N}=181) \quad$ Percent $(\%)$

a. Mode of delivery

i. Spontaneous virginal delivery (SVD)

ii. Caesarean Section (CS)

$\begin{array}{cc}149 & 82 \\ 32 & 18 \\ 4 & 2.2 \\ 28 & 15.5 \\ 2 & 1.1 \\ 4 & 2.2 \\ 8 & 4.4\end{array}$

b. Unspecified urinary tract infection

c. Any illness in pregnancy

d. Khan positive

e. Any discharge during pregnancy

f. Premature rapture of membranes

3.3. Risk factors associated with occurrence of neonatal sepsis among preterm neonates

The maternal risk factors associated with the occurrence of neonatal sepsis among the 41 preterm neonates who had laboratory confirmed neonatal sepsis were studied and the findings are summarized in Table 3.3. Illness in pregnancy and premature rapture of membranes during delivery were not statistically significant at $p=0.259$, $\mathrm{CI}=0.243-1.495$ and $(\mathrm{p}=0.358, \mathrm{CI}=0.050-3.134)$ respectively. Spontaneous virginal and caesarean section modes of delivery had $\mathrm{OR}=1.101, \chi 2=0.046, \mathrm{CI}=0.457-2.650 \mathrm{p}=0.830$ while prolonged rapture of membranes appeared to be associated with development of neonatal sepsis however did not reach statistical significance $(p=0.900)$. Urinary tract infection (UTI) and maternal antibiotics taken both had no association with development of preterm neonatal sepsis (see Table 3.3). 
Table 3.3: Association between maternal factors and development of neonatal sepsis

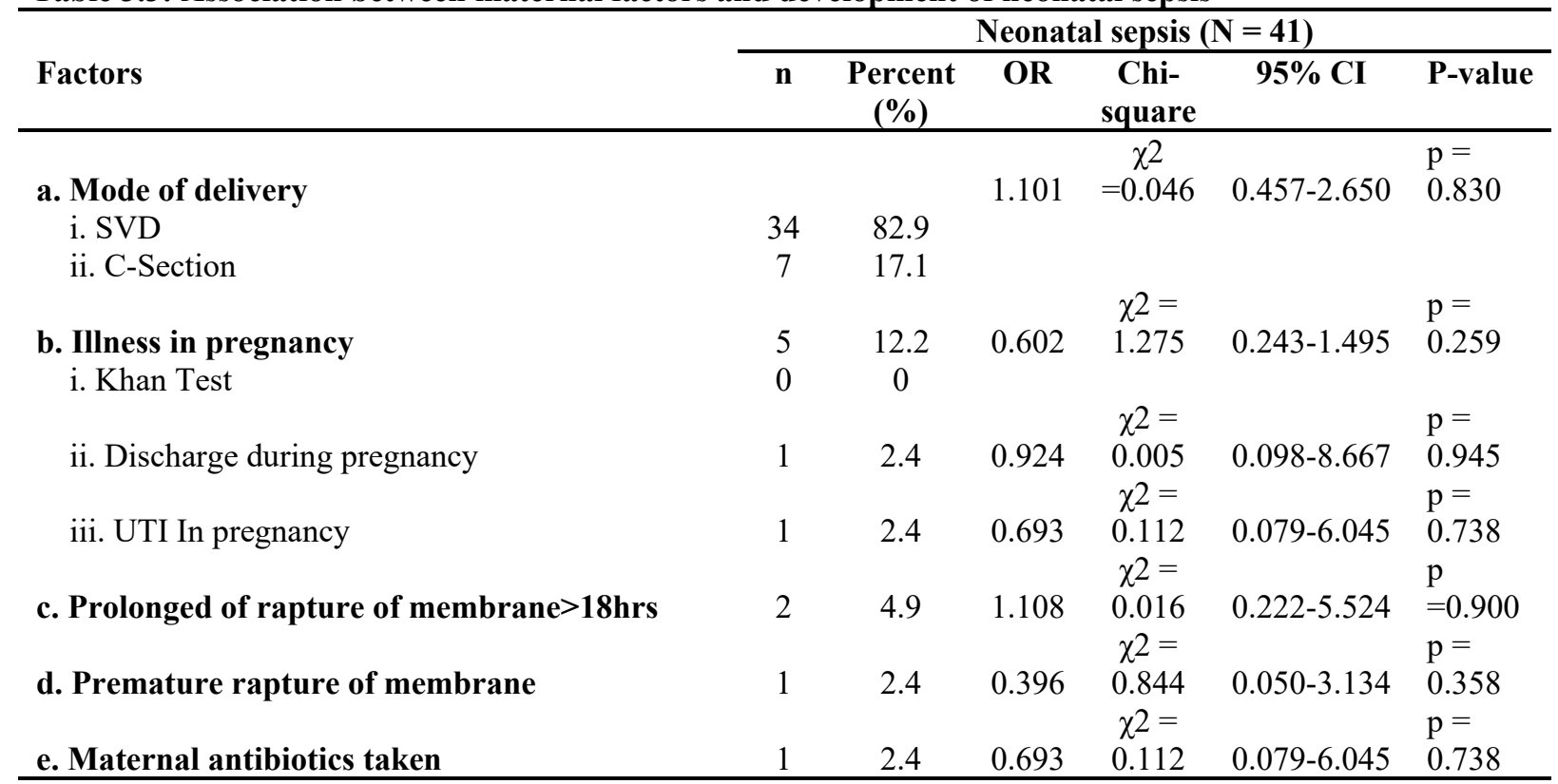

OR: Odds Ratio. p: Statistically significant(p<0.05), CI: Confidence Interval

The neonatal risk factors associated with the occurrence of neonatal sepsis were also determined by this study as summarized in Table 3.4 below. Foetal distress was strongly associated and statistically significant with development of neonatal sepsis with $\mathrm{OR}=2.244, \chi 2=5.633, \mathrm{CI}=1.143-4.407(\mathrm{p}=0.018)$. Low birth weight was also linked to development of neonatal sepsis $\mathrm{OR}=1.867, \chi^{2}=1.691, \mathrm{CI}=0.721-4.834(\mathrm{p}=0.194)$ and those preterm neonates who were not breast feeding well were highly likely to develop neonatal sepsis $\mathrm{OR}=1.688, \chi 2$ $=1.338, \mathrm{CI}=0.691-4.123(\mathrm{p}=0.247)$.

Table 3.4: Association between neonatal factors and development of neonatal sepsis

\begin{tabular}{|c|c|c|c|c|c|c|}
\hline \multirow[b]{2}{*}{ Variable } & \multicolumn{3}{|c|}{ Neonatal sepsis $(N=41)$} & \multirow[b]{2}{*}{$\begin{array}{c}\text { Chi- } \\
\text { square }\end{array}$} & \multirow[b]{2}{*}{$95 \% \mathrm{CI}$} & \multirow[b]{2}{*}{ P-value } \\
\hline & $\mathbf{n}$ & $\begin{array}{c}\text { Percent } \\
(\%)\end{array}$ & OR & & & \\
\hline a. Birth weight & & & 1.867 & $\chi^{2}=1.691$ & $0.721-4.834$ & $\mathrm{p}=0.193$ \\
\hline i. Normal & 36 & 87.8 & & & & \\
\hline ii. Low Birth weight & 5 & 12.2 & & & & \\
\hline iii. Central Line & 1 & 2.4 & 1.008 & $\chi^{2}=0.365$ & $0.993-1.023$ & $\mathrm{p}=0.574$ \\
\hline iv. Breast feeding & 41 & 100 & & & & \\
\hline v. Parenteral nutrition & 0 & 0 & & & & \\
\hline b. Foetal distress & 24 & 58.5 & 2.244 & $\chi^{2}=5.633$ & $1.143-4.407$ & $\mathrm{p}=0.018^{*}$ \\
\hline c. NOT Breast feeding well & 9 & 21.9 & 1.688 & $\chi 2=1.338$ & $0.691-4.123$ & $\mathrm{p}=0.247$ \\
\hline
\end{tabular}

OR: Odds Ratio. *: Statistically significant( $p<0.05)$, CI: Confidence Interval

\subsection{Microbial profiles of isolates associated with development of neonatal sepsis among preterms.}

i. Culturing findings

From the 181 blood cultures that were incubated at $37^{\circ} \mathrm{C}$ up to 14 days, $41(22.7 \%)$ turned positive by showing the presence of either haemolysis, clotting and agglutination. On further subculturing on 5\% sheep blood agar and purity plating on Mueller Hinton, $41(22.7 \%)$ bacteria were isolated as shown in Table 3.5 below. The isolated bacteria demonstrated either Beta (complete) haemolysis, Gamma (no haemolysis) and Alpha (partial haemolysis) on sheep blood agar. Gram staining and various biochemical tests were further performed to identify the species of interest.

ii. Gram staining findings

This was also performed on all the positive cultures $41(100 \%)$ to identify the isolated bacteria. The bacteria were separated into two groups, Gram positive cocci $35(85.4 \%)$ and they did present themselves as purple in colour while the Gram-negative rods $6(14.6 \%)$ did present themselves as pink in colour as shown in Table 3.5 below. 
Table 3.5: Culture and Gram staining

\begin{tabular}{lcc}
\hline Variables & $\begin{array}{c}\text { Frequency } \\
(\mathbf{n = 1 8 1})\end{array}$ & Percent (\%) \\
\hline a. Blood culture & $\mathbf{1 8 1}$ & $\mathbf{1 0 0}$ \\
i. Blood culture positive (Haemolysis /Clotting / Turbidity) & 41 & 22.7 \\
ii. Sub culture and purity plating & 41 & 22.7 \\
b. Gram staining (n=41) & $\mathbf{4 1}$ & $\mathbf{1 0 0}$ \\
i. Gram positive & 35 & 85.4 \\
ii. Gram negative & 6 & 14.6 \\
\hline
\end{tabular}

Table 3.6 describes the distribution profiles of bacteria that were isolated, Gram positive bacteria were 35 (85.4\%) majority comprised of Coagulase Negative Staphylococcus (CoNS) 31 (75.6\%). Among the CoNS, Staphylococcus epidermidis were 19 (46.3\%), Staphylococcus hemolyticus 5 (12.2\%), Staphylococcus hominis, Staphylococcus lentus and Staphylococcus warneri all were 2 isolates each (4.9\%), Staphylococcus saprophyticus one (2.4\%), Enterococcus ssp 3 (7.3\%) while Staphylococcus aureus was one (2.4\%). Gram negative bacteria $6(14.6 \%)$ comprised of Salmonella spp 3 (7.6\%) while Escherichia coli, Pseudomonas aeruginosa and Acinectobactor spp had one isolate each (2.4\%).

Table 3.6: Distribution of microbial profiles

\begin{tabular}{|c|c|c|c|}
\hline & & $\mathbf{n}$ & Isolates $\mathrm{N}=41$ \\
\hline \multicolumn{2}{|c|}{ Profile of isolates } & & Percent (\%) \\
\hline \multirow[t]{10}{*}{ i. } & Gram positive $\mathrm{N}=35(85.4 \%)$ & & \\
\hline & - Staphylococcus aureus & 1 & 2.4 \\
\hline & - Enterococcus ssp & 3 & 7.3 \\
\hline & - Coagulase negative Staphylococcus (CoNS) N $=31(75.6 \%)$ & & \\
\hline & - Staphylococcus epidermidis & 19 & 46.3 \\
\hline & - Staphylococcus haemolyticus & 5 & 12.2 \\
\hline & - Staphylococcus hominis & 2 & 4.9 \\
\hline & - Staphylococcus lentus & 2 & 4.9 \\
\hline & - Staphylococcus saprophyticus & 1 & 2.4 \\
\hline & - Staphylococcus warneri & 2 & 4.9 \\
\hline \multirow[t]{5}{*}{ ii. } & Gram negative $N=6(14.6 \%)$ & & \\
\hline & - Escherichia coli & 1 & 2.4 \\
\hline & - $\quad$ Pseudomonas aeruginosa & 1 & 2.4 \\
\hline & - Acinetobacter spp & 1 & 2.4 \\
\hline & - Salmonella spp & 3 & 7.3 \\
\hline \multicolumn{2}{|l|}{ Total } & 41 & 99.8 \\
\hline
\end{tabular}

\section{Discussion}

Child birth is a natural process after pregnancy has been carried to term, due to many physiological and environmental factors the neonate may be delivered before term (WHO., 2019). Many factors (maternal and neonatal) predispose the neonate to blood bacterial infection. For instance, it has been documented that environmental factors such as hospital acquired infections may contribute significantly to the development of neonatal sepsis (Spearman et al., 2015).

From this study 181 blood samples for culture were analysed and 41 were confirmed culture positive for neonatal sepsis giving a prevalence of $22.7 \%$. Globally sepsis is the major cause of neonatal morbidity and mortality responsible for $30-50 \%$ of the total number of neonatal deaths in a year among developing countries (Aijaz, 2012). This finding may be attributed to various factors among them is poor health care practice/management in both maternal and neonatal care or by environmental factors. Similar studies have been done in Kenya, for instance a study done at Kisii level five hospital (Muturi et al., 2018) found out a prevalence of $19.7 \%$ and at Kenyatta National Hospital a prevalence of $28.6 \%$ was reported (Geyt \& Hauck, 2016; Okube \& Komen, 2020). Both of these studies did indicate that maternal, neonatal and environmental factors were responsible for such prevalence. However, in another study done at NICU Arbaminch General Hospital South of Ethiopia contrasted our findings as prevalence of $78.3 \%$ was reported and was attributed to maternal and neonatal health related factors (Erkihun et al., 2019). Such differences in prevalence could be there globally could be due to geographical locations, different maternal and neonatal healthcare practices, policies and management.

Maternal factors under study were found out that mode of delivery; spontaneous virginal delivery (SVD) and Caesarean section (C-Section) with odds of 1.101 had a relationship with the development of neonatal sepsis although the association was not statistically significant. SVD may have attributed to development of neonatal 
sepsis due to exposure to virginal and faecal bacteria as reported in a study carried out in Ghana at a specialist hospital (Adatara., 2019), while C-section, preterm neonates may have been exposed due to invasive surgery, environmental factors and extended hospital stay (Bager, et al, 2010; Adatara., 2019). These findings do not concur with a study done in Ghana where mode of delivery was not associated with development of neonatal sepsis (Siakwa et al., 2014). Prolonged rupture of membranes (PROM) greater than 18 hours with odds of 1.108 was associated with neonatal sepsis, these could be due to chorioamnionitis (infection of membranes that surround the foetus). This finding is similar to findings of a study done in north India, which demonstrated a relationship between chorioamnionitis and PROM (Gupta, 2019).

Among the neonatal factors foetal distress was a single but most neonatal risk factor strongly linked to neonatal sepsis with OR of 2.244 with statistical significance of $p=0.0018$. Being the uncommon complication of labor where the fetus had breathing challenges and resuscitation urgently needed, contamination of equipment used could play a major role. This finding is similar to a study which found out that neonatal sepsis was associated with pneumonia like respiratory distress (Ghafoor et al., 2020).

Low birth weight was linked to development of NS with OR-1.867 with statistical significance of $p=0.193$. This may be an indicator of ill health and may require prompt attention and clinical management as it has been documented to predispose neonates to infections (Softić, 2017). This finding is similar to one documented in a study done in South Africa where low birth weight was an important risk factor as it was attributed to development of neonatal sepsis in preterms (Schrag et al., 2012).

Breast feeding is important for optimal growth and development; it protects neonates against septicaemia by providing defence factors (IgA antibodies) as described by (Gopalakrishna \& Hand 2020). Neonates who were not breast feeding well $(\mathrm{OR}=1.688)$ had high likelihood of developing sepsis. This could be attributed to array of possible other neonatal intrinsic factors like low birth weight, illness or alternative feeding contamination. However, these findings do not concur with those by Mugadza et al, (2017) who found out that early and correct breast-feeding initiation was associated with development of neonatal sepsis. Good maternal and neonatal health care practices and adherence to guidelines by health professionals may reduce the risk of developing sepsis.

Isolated bacterial profiles found to be responsible were predominantly Gram positive 35 (85.4\%) followed by Gram negative $6(14.6 \%)$. Our findings do concur with various studies that have indicated that NS in preterm neonates is commonly induced by Gram Positive bacteria as compared to Gram negative (El-Din et al., 2015; Thapa \& Sapkota, 2019). However, these findings differ from those obtained in a study done by Ghafoor et al., (2020) which did report that majority of isolates were Gram negative 44 (57.9\%) with Escherichia coli $(13.1 \%)$ being the most predominant isolate followed by Klebsiella pneumoniae (11.8\%), Acinetobacter spp (10.5\%), Pseudomonas aeruginosa (7.9\%), Enterobacter spp (5.3\%), Serratia spp (5.3\%), and lastly Proteus spp (3.9\%). Gram positive isolates were $32(42.1 \%)$, it's worth to note that such findings may differ from site to site due to different niche characteristics and cleanliness amongst other factors.

Coagulase negative Staphylococcus (CoNS) were the majority among the Gram positive isolates 31(75.6\%), this may be due to their ubiquitous nature of being found on human skin and being a leading cause of nosocomial infection (El-Din et al., 2015). It concurs with a study done in Egypt which found out CoNS as majority of isolates (El-Din et al., 2015). Among the CoNS, Staphylococcus epidermidis isolates were found to be the majority $19(46.3 \%)$, this may be attributed to their ability to form biofilms hence persisting in the environment and also their ability to resist a number of antimicrobial agents as documented in various studies (Seng et al., 2017; Sheikh et al., 2019). These findings are similar to those documented in a study done by Grace \& Obaro, (2019) in a systemic review of journals from randomly selected countries China, India, Kenya, Sweden, Nigeria, France, Zambia which also documented Staphylococcus epidermidis as the predominant isolates. Antibiotic resistance is corelated to biofilm formation among Coagulase Negative Staphylococcus (CoNS) especially in Staphylococcus epidermidis (Sheikh et al., 2019). Biofilm formation has been documented to be the main virulence determinant among the bacteria responsible for NS, it occurs especially in invasive procedures that are involved in management of neonatal sepsis (Le et al., 2018). This has resulted to antimicrobial resistance as bacteria are able to persist in environment for long due to presence of resistant genes in the biofilms, hence prolonging treatment (Sheikh et al., 2019).

\section{Conclusions and recommendation}

The prevalence of NS at $\mathrm{KCH}$ was determined to be at $22.7 \%$ among preterm neonates with both maternal factors including mode of delivery, Prolonged Rupture of Membranes (PROM) and neonatal factors including foetal distress, low birth weight and poor breast feeding being the major risk factors. On the profiles of organisms causing neonatal sepsis, Gram positive isolates were the majority comprising of CoNS with Staphylococcus epidermidis being the majority. There is need to assess the correlation between the specific maternal and neonatal risk factors and common circulating bacterial profiles at Kitale County Hospital New Born Unit. 
Acknowledgments: We would like to thank the study participants, Kitale County Hospital management, Kitale County Hospital new-born unit Staff and Kitale County Hospital Laboratory Microbiology and Molecular biology staff; Godfrey Sande, Warda Hussein Mohammed, and Fredrick Mutai.

\section{Author's Contribution}

EPK, EOO and GKM were involved in the conception and design of the study. EPK supervised interviews. EPK performed laboratory tests and analysis, EPK analysed the data and prepared the manuscript. EOO and GKM provided guidance and mentorship during the implementation of the study. All authors reviewed and approved the final manuscript. EPK takes the first authorship responsibilities.

\section{References}

Adams-Chapman I, Hansen NI, Stoll BJ, et al. NICHD Research Network. Neurodevelopmental outcome of ELBW infants with posthemorrhagic hydrocephalus requiring shunt insertion. Pediatrics. 2008; $121:$ e1167-77.

Adatara, P., Afaya, A., Salia, S. M., Afaya, R. A., Konlan, K. D., Agyabeng-Fandoh, E., . . . Boahene, I. G. (2019). Risk Factors Associated with Neonatal Sepsis: A Case Study at a Specialist Hospital in Ghana. The Scientific World Journal, 2019, 1-8. doi:10.1155/2019/9369051

Ahmed, S., Mokhtar, E., El-Kholy, I., Essawy, A. E., El-Din, A., \& Shetaia, Y. (2019). Fungal neonatal and infantile sepsis in Egypt: Risk factors and identification of fungal isolates. African Journal of Clinical and Experimental Microbiology, 21(1), 14. doi:10.4314/ajcem.v21i1.2

Aijaz, N., Huda, N., \& Kausar, S. (2012). Disease Burden of NICU, at a Tertiary Care Hospital, Karachi. Journal of the Dow University of Health Sciences (JDUHS), 6(1), 32-35. Retrieved from http://jduhs.com/index.php/jduhs/article/view/32

Bager, P., Simeonsen, J., Ethelberg, S., \& Frisch, M. (2010). Cesarean Delivery and Risk of Intestinal Bacterial Infection. The Journal of Infectious Diseases, 201(6), 898-902. doi:10.1086/650998

Behera B, Mathur P, Gupta B.. Blood culture gram stain, acridine orange stain and direct sensitivity-based antimicrobial therapy of bloodstream infection in patients with trauma. Indian $\mathrm{J}$ Med Microbiol. 2010;28(2):138-142. 10.4103/0255-0857.62491

Berkley, J. A., Lowe, B. S., Mwangi, I., Williams, T., Bauni, E., Mwarumba, S., . . . Scott, J. A. (2005). Bacteremia among Children Admitted to a Rural Hospital in Kenya. New England Journal of Medicine, 352(1), 39-47. doi:10.1056/nejmoa040275

Born too soon. (2019). Retrieved January 26, 2021, from https://www.who.int/maternal child adolescent/documents/born too soon/en/

Camacho-Gonzalez A., Spearman P.W. \& Stoll B.J. (2013). Neonatal infectious diseases:evaluation of neonatal sepsis. Pediatr Clin North Am. 60(2):367-89

Cochran, W. (2007). Sampling Techniques, 3Rd Edition. Retrieved January 26, 2021, from https://books.google.com/books/about/Sampling Techniques 3Rd Edition.html?id=xbNn41DUrNwC

Dolin, H. H., Papadimos, T. J., Chen, X., \& Pan, Z. K. (2019). Characterization of Pathogenic Sepsis Etiologies and Patient Profiles: A Novel Approach to Triage and Treatment. Microbiology Insights, 12, 117863611882508. doi:10.1177/1178636118825081

El-Din, E. M., El-Sokkary, M. M., Bassiouny, M. R., \& Hassan, R. (2015). Epidemiology of Neonatal Sepsis and Implicated Pathogens: A Study from Egypt. BioMed Research International, 2015, 1-11. doi: $10.1155 / 2015 / 509484$

Erkihun, K., Mesfin, M., Direslegn, M., Sultan, H., \& Negussie, B. (2019). Determinants of neonatal sepsis among neonates admitted in a neonatal intensive care unit at Jinka General Hospital, Southern Ethiopia. International Journal of Nursing and Midwifery, 11(3), 18-24. doi:10.5897/ijnm2018.0335

Esposito, S., \& Principi, N. (2019). Adjunctive therapy to treat neonatal sepsis. Expert Review of Clinical Pharmacology, 13(1), 65-73. doi:10.1080/17512433.2020.1699790

Gebrehiwot, A., Lakew, W., Moges, F., Moges, B., Anagaw, B. \& Yismaw, G. (2012). Bacterial profile and drug susceptibility pattern of neonatal sepsis in Gondar University Hospital, Gondar northwest Ethiopia. Der Pharmacia Lettre, 4(6): 1811-1816

Getabelew, A., Aman, M., Fantaye, E., \& Yeheyis, T. (2018). Prevalence of Neonatal Sepsis and Associated Factors among Neonates in Neonatal Intensive Care Unit at Selected Governmental Hospitals in Shashemene Town, Oromia Regional State, Ethiopia, 2017. International Journal of Pediatrics, 2018, 1-7. doi: $10.1155 / 2018 / 7801272$

Geyt, J. L., \& Hauck, S. (2016). G272 Epidemiological trends of neonatal sepsis in a county referral hospital in central Kenya. Archives of Disease in Childhood, 101(Suppl 1). doi:10.1136/archdischild-2016-310863.264

Ghafoor, T., Hussanain, A., Qureshi, M., Mehmood, T., \& Ali, L. (2020). Antimicrobial susceptibility pattern of blood culture isolates from patients with suspected neonatal sepsis in a tertiary care hospital in Pakistan. Sri 
Lankan Journal of Infectious Diseases, 10(1), 30. doi: 10.4038/sljid. v 10i1.8244

Gopalakrishna, K., \& Hand, T. (2020). Influence of Maternal Milk on the Neonatal Intestinal Microbiome. Retrieved October 14, 2020, from https://www.mdpi.com/2072-6643/12/3/823

Grace, J.-U. A., \& Obaro, S. K. (2019). A Systematic Review of Coagulase-Negative Staphylococci in Neonatal Sepsis. Clinical Microbiology: Open Access, 08(01). doi: 10.4172/2327-5073.1000326

Groer MW;Gregory KE;Louis-Jacques A;Thibeau S;Walker WA;. (2015.). The very low birth weight infant microbiome and childhood health. Retrieved September 10, 2020, from https://pubmed.ncbi.nlm.nih.gov/26663857/

Guo, J., Luo, Y., Wu, Y., Lai, W., \& Mu, X. (2019). Clinical Characteristic and Pathogen Spectrum of Neonatal Sepsis in Guangzhou City from June 2011 to June 2017. Medical Science Monitor, 25, 2296-2304. doi: $10.12659 / \mathrm{msm} .912375$

Gupta, D. P. (2019). Relationship of chorioamnionitis with neonatal sepsis in preterm premature rupture of membranes- A Study. Journal of Medical Science And Clinical Research, 7(11). doi: $10.18535 / \mathrm{jmscr} / \mathrm{v} 7 \mathrm{i} 11.168$

Howson, E.P., Kinney, M.V. \& Lawn, J.E. (2014). Born too soon: the global action report on preterm birth. Geneva: WHO.Int. J. Infect. Dis., 8 (2004), pp. 39-45

Hussein, E. F. (2016). Isolation, Identification and Antibiotic Susceptibility of pathogenic Bacteria Isolated from Clinical Samples. IOSR Journal of Pharmacy and Biological Sciences, 11(04), 27-39. doi:10.9790/30081104022739

Karen Reiner. (2010). Catalase test protocol. November 2010. Category Protocol.Kenya

Le, K. Y., Park, M. D., \& Otto, M. (2018). Immune Evasion Mechanisms of Staphylococcus epidermidis Biofilm Infection. Frontiers in Microbiology, 9. doi:10.3389/fmicb.2018.00359

Leber, A. L. (2016). Clinical microbiology procedures handbook. Washington, DC: ASM Press.

Lutsar, I., Chazallon, C., Carducci, F. I., Trafojer, U., Abdelkader, B., Cabre, V. M., . . A Aboulker, J. (2014). Current management of late onset neonatal bacterial sepsis in five European countries. European Journal of Pediatrics. doi:10.1007/s00431-014-2279-5

Masanja, P. P., Kibusi, S. M., \& Mkhoi, M. L. (2019). Predictors of Early Onset Neonatal Sepsis among Neonates in Dodoma, Tanzania: A Case Control Study. Journal of Tropical Pediatrics, 66(3), 257-266. doi:10.1093/tropej/fmz062

Medlock, S., Ravelli, A.C.J. \& Tamminga P. (2014). Prediction of mortality in very premature infants: a systematic review of prediction models. Plos One. 2011 [citado in 2014 jul. 07];6(9): e23441.doi/10.1371/journal.pone.0023441

Mugadza, G., Zvinavashe, M., Gumbo, F. Z., \& Pedersen, B. S. (2017). Early breastfeeding initiation and incidence of neonatal sepsis in Chipinge District Zimbabwe. International Journal of Contemporary Pediatrics, 5(1), 1. doi: 10.18203/2349-3291.ijcp20175564

Murthy, S., Godinho, M. A., Guddattu, V., Lewis, L. E., \& Nair, N. S. (2019). Risk factors of neonatal sepsis in India: A systematic review and meta-analysis. Plos One, 14(4). doi:10.1371/journal. pone. 0215683

Muturi, C. (2018). Prevalence of sepsis among neonates admitted to Kisii level 5 hospital. Retrieved October 12, 2020, from http://erepository.uonbi.ac.ke/handle/11295/95125

Nathan S Gollehon, M. (2019). Neonatal Sepsis. Retrieved October 12, 2020, from https://emedicine.medscape.com/article/978352-overview

Nunes AR, KLee, TO'Riordan. 2016, Global health. gh. Bmj. Com

Nyma, Z., Rahman, M., Hasan, S. M., Roby, N. U., Khanam, F., Alam, M. E., \& Ali, M. (2020). Prevalence and Associated Risk Factors of Sepsis among Neonates Admitted into Neonatal Intensive Care Units of Public Hospitals in Dhaka. Cureus. doi:10.7759/cureus.7461

Okube, O. T., \& Komen, M. (2020). Prevalence and Predictors of Neonatal Sepsis among Neonates Admitted at the Newborn Unit of Kenyatta National Hospital, Nairobi, Kenya. Open Journal of Obstetrics and Gynecology, 10(09), 1216-1232. doi:10.4236/ojog.2020.1090114

Schrag, S. J., Cutland, C. L., Zell, E. R., Kuwanda, L., Buchmann, E. J., Velaphi, S. C., ... Madhi, S. A. (2012). Risk Factors for Neonatal Sepsis and Perinatal Death Among Infants Enrolled in the Prevention of Perinatal Sepsis Trial, Soweto, South Africa. The Pediatric Infectious Disease Journal,31(8), 821-826. doi: 10.1097/inf.0b013e31825c4b5a

Seale, A.C., Blencowe, H., Manu, A.A., Nair, H., Bahl, R., Qazi, S.A. \& Lawn, J.E. (2014). Estimates of possible severe bacterial infection in neonates in sub-Saharan Africa, south Asia, and Latin America for 2012: a systematic review and meta-analysis. Lancet Infect Dis. 14(8):731-741. doi: 10.1016/S14733099(14)70804-7.

Seng, R., Kitti, T., Thummeepak, R., Kongthai, P., Leungtongkam, U., Wannalerdsakun, S., \& Sitthisak, S. (2017). Biofilm formation of methicillin-resistant coagulase negative staphylococci (MR-CoNS) isolated from community and hospital environments. Plos One, 12(8). doi:10.1371/journal. pone.0184172 
Shane, A. L., Sánchez, P. J., \& Stoll, B. J. (2017). Neonatal sepsis. The Lancet, 390(10104), 1770-1780. doi:10.1016/s0140-6736(17)31002-4

Sheikh, A. F., Dezfuli, A. A., Navidifar, T., Fard, S. S., \& Dehdashtian, M. (2019). Association between biofilm formation, structure and antibiotic resistance in Staphylococcus epidermidis isolated from neonatal septicemia in southwest Iran. Infection and Drug Resistance, Volume 12, 1771-1782. doi:10.2147/idr.s204432

Siakwa, M., Kpikpitse, M., upepi, D. \& Mohamed, S.S. (2014). Neonatal sepsis in rural Ghana: A case control study of risk factors in a birth cohort. IJRMHS \& K.A.J. September; 4(5) 77-88.

Sorsa, A. (2019, May). Epidemiology of Neonatal Sepsis and Associated Factors Implicated: Observational Study at Neonatal Intensive Care Unit of Arsi University Teaching and Referral Hospital, South East Ethiopia. Retrieved September 11, 2020, from https://www.ncbi.nlm.nih.gov/pmc/articles/PMC6689722/

Spearman, P.W., Andres, Camacho-Gonzaleze. \& Barbara, J. Stoll. (2015). Neonatal Infectious Diseases: Evaluation of Neonatal Sepsis. PMC 2015 Apr. 22. 2015

Stoll BJ;Hansen NI;Bell EF;Shankaran S;Laptook AR;Walsh MC;Hale EC;Newman NS;Schibler... (2010.). Neonatal outcomes of extremely preterm infants from the NICHD Neonatal Research Network. Retrieved September 11, 2020, from https://pubmed.ncbi.nlm.nih.gov/20732945/

United Nations International Children's Fund (UNICEF) (2018) The Neonatal Period Is the Most Vulnerable Time for a Child.

Wayne, P.A. (2007). Principles and procedures for Blood culture. Approved Guideline. CLSI document M47-A. Clinical and Laboratory Standards Institute (CLSI). 2007. 